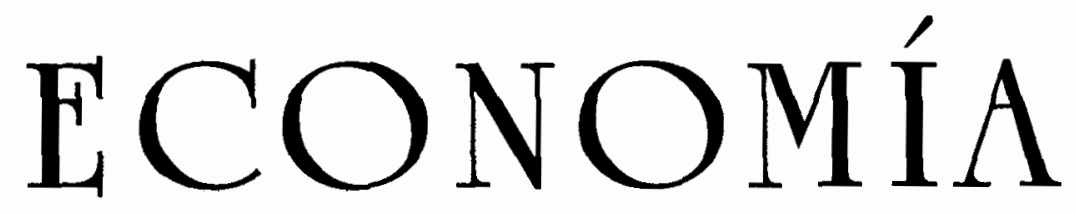

Revista del Departamento de Economía Pontificia Universidad Católica del Perú

volumen XXIV No 48 diciembre 2001 


\section{Contenido}

PRESENTACIÓN

ARTICULOS

Las relaciones entre los sectores formal e informal. Una exploración sobre su naturaleza

VÍCTOR E. TOKMAN

Costo laboral y competitividad en el sector manufacturero de América Latina, 1990-1998

VÍCTOR E. TOKMAN Y DANIEL MARTÍNEZ

Oferta laboral y producto: 1970-1999

CECILIA GARAVITO

Reforma en la contratación y despido en el Perú de los 90: lecciones y perspectivas

JUAN CHACALTANA J.

De la informalidad a la modernidad

VÍCTOR E. TOKMAN

La calidad del empleo: lecciones y tareas

179

RICARDO INFANTE Y MÁXIMO VEGA-CENTENO 


\title{
Costo laboral y competitividad en el sector manufacturero de América Latina
}

\author{
Victor E. Tokman \\ Daniel Martínez*
}

\section{RESUMEN}

En este artículo se examina la reducción de los costos laborales como un factor que contribuye a elevar la competitividad de las empresas industriales. Se pasa revista, en primer lugar, a los costos laborales no salariales, tanto de los trabajadores con contrato indefinido como de aquellos con contrato temporal y de los no registrados, con el propósito de mostrar las diferencias existentes en el costo laboral no salarial según el tipo de contrato o la calidad de no registrados de los trabajadores, así como el impacto de estas diferencias sobre el costo laboral de cada tipo y sobre el costo medio. Enseguida se examina la evolución del costo laboral en la industria y como este adquiere diferentes magnitudes según el deflactor que se use, dado el cambio en los precios relativos que acompañó a los primeros años del proceso de apertura económica y comercial en la región. A continuación se analiza la evolución de los costos laborales en la industria por tipo de contrato, así como los cambios en el costo laboral medio en la industria que resulta de la doble estrategia de reducir los costos laborales no salariales y de modificar la estructura por tipos de contrato en el empleo asalariado; se describe el efecto del rezago cambiario sobre el costo laboral medio y la competitividad, y se calcula cuál habría sido la evolución de esta última de no haberse producido dicho rezago. Por último, se formulan algunas propuestas para elevar la competitividad laboral en los países de la región.

\begin{abstract}
In this paper the reduction of labor costs is examined as a factor that contributes to increase the competitiveness of manufacturing firms. It first reviews non-wage labor costs in the case of workers with indefinite labor contracts, workers with temporary contracts, and those non-registered, with the intention of showing the differences that exist in non-wage labor costs according to the type of contract or the quality of non-registered of the workers, as well as the impact of these differences on the labor costs of each type and on the average cost. It then examines the evolution of labor costs in manufacturing, and how their magnitude varies depending on the deflator that is used, given the change in relative prices that accompanied the first years of the processes of economic and commercial liberalization in the region. It then analyzes the evolution of labor costs in manufacturing according to the type of con-
\end{abstract}

* Funcionario de la Oficina Regional para las Américas de la OIT. Los juicios contenidos en este trabajo no representan necesariamente la posición de la OIT. 
tract, as well as the changes in the average labor cost in manufacturing that resulted from the strategy of both reducing non-wage labor costs and modifying the structure of employment by type of contract; the impact of exchange rate overvaluation on the average labor cost and competitiveness is described, and estimates the possible evolution of competitiveness in the absence of the exchange overvaluation. Finally, some suggestions seeking labor competitiveness in the countries of the region are made.

\section{Introducción}

Algunas de las más importantes modificaciones a la legislación laboral y previsional de los últimos años han apuntado a reducir los costos laborales. Se ha argumentado que, por ser el costo laboral un componente importante del costo total de producción, su rebaja provocará una reducción del costo del bien producido o del servicio prestado, haciendo más competitivas a las empresas beneficiadas por esta politica.

La política de reducción del costo laboral se traduce en dos estrategias, que en ocasiones se aplican simultáneamente: por una parte, reducir las contribuciones sociales y los impuestos al trabajo, es decir, el componente no salarial del costo laboral total, y por otra, incentivar (a través de subsidios y/o exoneraciones tributarias) la contratación de determinados tipos de trabajadores, especialmente jóvenes sin experiencia laboral y desempleados de larga duración.

El objetivo de esta segunda estrategia es abaratar el costo de contratación de estos trabajadores y, por esta vía, fomentar su empleo. En el caso de los jóvenes, por ejemplo, es preciso equilibrar el costo relativo de emplear a un joven sin experiencia - de menor productividad-con el de emplear a un trabajador adulto con experiencia. Este equilibrio se logra si el Estado absorbe una parte del costo laboral no salarial de esa persona (principalmente los costos previsionales), reduciendo asi para el empleador las cargas o impuestos al trabajo, o si se libera al empresario de toda o parte de la obligación contributiva (laboral) que es su responsabilidad.

Esta nueva orientación de la legislación laboral y previsional (que, desde luego, también persigue otros objetivos, además de la reducción de costos) es motivo de debates. Los empresarios consideran, en general, que la reducción del costo laboral, junto con la mayor flexibilidad en las 
modalidades de contratación y con la movilidad de los trabajadores dentro de las empresas, permite que éstas se tornen más competitivas, pues pueden ofrecer sus productos a precios más convenientes y adecuar con más facilidad su organización y el número de sus trabajadores a los cambios en la demanda.

Los trabajadores, por su parte, si bien reconocen la importancia de reducir los costos empresariales, temen consecuencias adversas en sus ingresos y/o en la extensión y calidad de los sistemas de protección, especialmente en materia de salud y de pensiones.

Cabe preguntarse entonces si es necesario disminuir los costos laborales para tornar más competitivas a las empresas. El presente trabajo trata de dar respuesta a esta interrogante. Por razones de disponibilidad de información, hemos limitado el análisis al sector manufacturero. Asimismo, la productividad está referida al trabajo y no al total de los factores. ${ }^{1}$

Este artículo actualiza y amplía una primera versión de este estudio (OIT: 1997), con el propósito de estimar los cambios en el nivel de competitividad a partir de las variaciones de la productividad y del costo laboral medio. Este último aspecto (el costo laboral medio) no fue considerado en la publicación original, ya que en esa ocasión el costo laboral analizado era el de un trabajador con contrato de duración indeterminada. Sin embargo, dado que en los últimos años ha aumentado significativamente la demanda de trabajadores por tiempo determinado y, más aún, la de trabajadores no registrados y sin protección social, se consideró que el costo de un asalariado con contrato indefinido no representaba adecuadamente el costo laboral medio en el sector industrial. Por lo tanto, hemos estimado el costo medio resultante de la suma de los costos de cada tipo de contrato ( $y$ de los trabajadores sin contrato) ponderados por el peso de cada una de estas modalidades en la estructura del empleo industrial. De igual modo, los datos sobre productividad laboral aquí utilizados se refieren al valor agregado por hora trabajada y no, como en la publicación original, a la producción física por hora trabajada.

1 Aunque la productividad asi definida se refiere a un solo factor, está por lo general correlacionada con la productividad total de los factores. Hofman (1996) muestra que este es el caso para Argentina, Chile y México durante el período 1950-1992. 


\section{EVOLUCIÓN DEL COSTO LABORAL NO SALARIAL EN EL SECTOR MANUFACTURERO}

Generalmente el costo laboral no salarial se calcula como el porcentaje del salario bruto que el empleador debe contribuir adicionalmente para financiar las prestaciones sociales que establece la legislación de cada país. En la mayoría de los estudios se incluyen, además, los salarios diferidos en el tiempo y que están constituidos por el pago de gratificaciones (decimotercer mes o más) y las vacaciones. Sin embargo, tanto las contribuciones de cargo del empleador como los salarios diferidos por concepto de gratificaciones y vacaciones se estiman sobre la base de la legislación vigente para los asalariados con contrato indefinido, sin tomar en cuenta que para los asalariados con contrato de duración determinada en algunos paises se establece un tratamiento diferente y que para los trabajadores sin contrato el empleador no efectúa ninguna $o$ casi ninguna contribución social. En esta sección por lo tanto, se distingue entre el costo laboral no salarial de los trabajadores bajo cada una de las tres modalidades indicadas.

\section{Costo laboral no salarial de los trabajadores con contrato indefinido}

En los paises considerados, la evolución del aporte del trabajador ${ }^{2}$ ha sido la siguiente: en Argentina subió del 14\% del salario bruto en 1980 , al $16 \%$ en 1990 y al $17 \%$ en 1998 (cuadro 1). En el Perú, aumentó del $6 \%$ en 1990 al $19 \%$ en 1994 , por efecto de la reforma del sistema de pensiones, y con posterioridad se redujo al $11.4 \%$. En los demás países se mantuvo constante: $21 \%$ en Chile y entre 9 y $5 \%$ en Brasil, Colombia y México. Debe notarse que en Chile, al igual que en Perú, el aporte del trabajador se habia elevado con anterioridad debido a la privatización del sistema de pensiones.

El mayor aporte de los trabajadores en Chile y Perú es consecuencia de la reforma del régimen de pensiones, que trasladó la responsabilidad del financiamiento de este régimen exclusivamente a los trabajadores: es decir, ahora éstos deben efectuar, además de sus propios aportes al

2 Se denominará "aporte" a los recursos descontados del salario bruto del trabajador para financiar prestaciones laborales, y "contribuciones" a los recursos adicionales al salario que, con el mismo fin, están a cargo del empleador. 
antiguo régimen, los que hacían sus empleadores. Se compensó este traslado con un aumento proporcional del salario bruto.

Por el lado de los empleadores, sus contribuciones laborales como porcentaje del salario bruto evolucionaron así: en Argentina se redujeron de $59.6 \%$ en 1980 a $56.1 \%$ en 1990 y a $44.8 \%$ en 1998 (cuadro 1); en Brasil, aumentaron ligeramente del $57.6 \%$ en 1990 al $58.2 \%$ del salario bruto en 1994 y se mantienen en ese nivel; en Chile son de $38 \%$ a partir de la reforma laboral de los años ochenta; en Colombia pasaron del $47.6 \%$ en 1980 al $46.8 \%$ en 1990 y al $49.0 \%$ en 1998 , y en Perú se contrajeron del $66.8 \%$ en 1990 al $62.9 \%$ en 1994 , para elevarse posteriormente al $65.6 \%$.

Las contribuciones a cargo del empleador varian entre cerca del $40 \%$ en Perú y el $27.5 \%$ en Chile. En Argentina alcanzan a $31 \%$ y en Brasil, Colombia y México a alrededor de $35 \%$.

Los cálculos de los costos laborales no salariales efectuados en este trabajo difieren de las estimaciones realizadas en otros estudios e incluso en estudios anteriores de la propia OIT. Ello se debe a dos motivos. En primer lugar, las alícuotas utilizadas en rubros como seguro de accidentes, subsidio familiar e indemnización por despido son promedios estimados, los que se reajustan anualmente sobre la base de la información que proporcionan las empresas y organismos oficiales para el año anterior al de la fecha del estudio. En consecuencia, a medida que los estudios se actualizan, se modifican las alícuotas para reflejar mejor to efectivamente ocurrido. En segundo lugar, en algunos países se ha modificado la metodología de cálculo. Es el caso, por ejemplo, de los ingresos complementarios en Chile; estos se han estimado en $19.8 \%$ del salario bruto al tener en cuenta que la mayor parte de los asalariados chilenos perciben un ingreso mensual equivalente a dos salarios mínimos, a diferencia de anteriores estudios en los que se consideraba un ingreso medio equivalente a un salario mínimo y se aplicaba una alícuota del $25 \%$. Además, no se incluye en estos cálculos el costo de rubros como días feriados y domingos, licencia por maternidad, por enfermedad, etc., por las razones que se explican en OIT (1997). 


\section{Cuadro 1}

Argentina, Brasil, Chile, Colombia, México y Perú: Composición del costo laboral no salarial de trabajadores permanentes y temporales

Argentina

\begin{tabular}{|c|c|c|c|c|c|}
\hline & \multirow{2}{*}{\begin{tabular}{c|}
1980 \\
Permanentes
\end{tabular}} & \multirow{2}{*}{$\begin{array}{c}1990 \\
\text { Permanentes }\end{array}$} & \multirow{2}{*}{$\begin{array}{c}1994^{a} \\
\text { Permanentes }\end{array}$} & \multicolumn{2}{|c|}{1998} \\
\hline & & & & Permanentes & Temporales \\
\hline A. Remuneración bruta & 100.0 & 100.0 & 100.0 & 100.0 & 100.0 \\
\hline Remuneración neta mensualizada ${ }^{b}$ & 97.1 & 95.1 & 94.1 & 91.3 & \\
\hline B.Aportes del trabajador & 14.0 & 16.0 & 17.0 & 17.0 & \\
\hline Pensiones & 11.0 & 10.0 & 11.0 & 11.0 & \\
\hline Obras sociales ${ }^{c}$ & 4.0 & 6.0 & 6.0 & 6.0 & \\
\hline C. Contribuciones del empleador & 59.6 & 56.1 & 56.1 & 44.8 & 30.9 \\
\hline 1. Contribuciones & 43.9 & 40.4 & 40.4 & 29.1 & 17.7 \\
\hline Previsión (jubilación) & 15.0 & 11.0 & 16.0 & 9.9 & 5.0 \\
\hline Obras sociales & 4.5 & 8.0 & 8.0 & 6.2 & 5.1 \\
\hline Asignación familiar & 12.0 & 9.0 & 7.5 & 4.7 & 2.3 \\
\hline Fondo de desempleo & - & - & 1.5 & 0.9 & 0.5 \\
\hline$I P D^{d}$ & 5.4 & 5.4 & 5.4 & 5.4 & 2.8 \\
\hline Accidentes & 2.0 & 2.0 & 2.0 & 2.0 & 2.0 \\
\hline Vivienda & 5.0 & 5.0 & - & - & - \\
\hline 2. Otros costos para el empleador & 15.7 & 15.7 & 15.7 & 15.7 & 13.2 \\
\hline Pagos complementarios ${ }^{\mathrm{e}}$ & 8.3 & 8.3 & 8.3 & 8.3 & 8.3 \\
\hline Vacaciones & 7.4 & 7.4 & 7.4 & 7.4 & 4.9 \\
\hline D. Costo total $(A+C)$ & 159.6 & 156.1 & 156.1 & 144.8 & 130.9 \\
\hline $\mathrm{C} / \mathrm{D}(\%)$ & 37.3 & 35.9 & 35.9 & 30.9 & 23.6 \\
\hline
\end{tabular}

Brasil

\begin{tabular}{|l|r|r|r|r|}
\hline & 1990 & 1994 & \multicolumn{2}{|c|}{1998} \\
\cline { 4 - 5 } & Permanentes & Permanentes & Permanentes & Temporales \\
\hline A. Remuneración bruta & 100.0 & 100.0 & 100.0 & 100.0 \\
Remuneración neta mensualizada & 99.3 & 99.3 & 99.3 & \\
B. Aportes del trabajador & 9.0 & 9.0 & 9.0 & \\
Pensiones & 9.0 & 9.0 & 9.0 & \\
C. Contribuciones del empleador & 57.6 & 58.2 & 58.2 & 37.2 \\
1. Contribuciones & 38.2 & 38.8 & 38.8 & 25.9 \\
Seguridad Social & 20.0 & 20.0 & 20.0 & 20.0 \\
Serv. Social Ind. & 1.5 & 1.5 & 1.5 & 0.75 \\
Serv. Apren. Ind. & 1.0 & 1.0 & 1.0 & 0.5 \\
Inst. Nac. de Coloniz. y Ref. Agr. & 0.2 & 0.2 & 0.2 & 0.1 \\
Salario educación & 2.5 & 2.5 & 2.5 & 1.25 \\
Serv. Brasileño de Apoyo a la Peq. & & & & \\
y Med. Empresa & - & 0.6 & 0.6 & 0.3 \\
Fondo de Garantía por Tiempo de Servicio & 8.0 & 8.0 & 8.0 & 2.0 \\
Accidentes & 2.0 & 2.0 & 2.0 & 1.0 \\
Indemnización por despido & 3.0 & 3.0 & 3.0 & - \\
2. Otros costos para el empleador & 19.4 & 19.4 & 19.4 & 11.3 \\
Pagos complementarios & 8.3 & 8.3 & 8.3 & 8.5 \\
Vacaciones & 11.3 & 11.3 & 11.1 & 2.8 \\
D. Costo total (A+C) & 157.6 & 158.2 & 158.2 & 137.2 \\
C/D (\%) & 36.5 & 36.8 & 36.8 & 27.1 \\
\hline
\end{tabular}




\begin{tabular}{|l|c|c|c|}
\hline \multicolumn{1}{|c|}{ Chile } \\
\hline & 1990 & 1994 & 1998 \\
Permanentes & Permanentes & $\begin{array}{c}199 \\
\text { Permanentes }\end{array}$ \\
\hline A. Remuneración bruta & 100.0 & 100.0 & 100.0 \\
Remuneración neta & 98.7 & 98.7 & 98.7 \\
B. Aportes del trabajador & 21.1 & 21.1 & 21.1 \\
Pensiones & 13.5 & 13.5 & 13.5 \\
Salud & 7.0 & 7.0 & 7.0 \\
Accidentes & 0.6 & 0.6 & 0.6 \\
C.Contribuciones empleador & 38.0 & 38.0 & 38.0 \\
1. Contribuciones & 10.9 & 10.9 & 10.9 \\
Indemnización despido & 8.3 & 8.3 & 8.3 \\
Accidentes & 2.6 & 2.6 & 2.6 \\
2. Otros costos para empleador & 27.1 & 27.1 & 27.1 \\
Vacaciones & 7.3 & 7.3 & 7.3 \\
Pagos complementarios & 19.8 & 19.8 & 19.8 \\
D. Costo total $(A+C)$ & 138.0 & 138.0 & 138.0 \\
C/D (\%) & 27.5 & 27.5 & 27.5 \\
\hline
\end{tabular}

Colombia

\begin{tabular}{|l|c|c|c|c|}
\hline & \multicolumn{2}{|c|}{1988} & \multicolumn{2}{c|}{1996} \\
\cline { 2 - 5 } & Permanentes & Temporales & Permanentes & Temporales \\
\hline A. Remuneración bruta & 100.0 & 100.0 & 100.0 & 100.0 \\
Remuneración netab & & & 100.9 & 100.9 \\
B.Aportes del trabajador & & & 7.4 & 7.4 \\
Pensiones & & & 3.4 & 3.4 \\
Saludk & & & 4.0 & 4.0 \\
Accidentes & & & & \\
C.Contribuciones empleador & 47.6 & 29.3 & 52.9 & 52.9 \\
1. Contribuciones & 33.5 & 29.3 & 38.8 & 38.8 \\
$\quad$ Saludk & 4.7 & 4.7 & 8.0 & 8.0 \\
Pensiones & 4.3 & 4.3 & 10.1 & 10.1 \\
$\quad$ Indemnización despido & 13.5 & 9.3 & 9.3 & 9.3 \\
$\quad$ Servicio Nacional de Aprendizaje & 2.0 & 2.0 & 2.0 & 2.0 \\
$\quad$ Accidentes & 2.0 & 2.0 & 2.4 & 2.4 \\
Asignaciones familiares & 4.0 & 4.0 & 4.0 & 4.0 \\
Instituto Bienestar Familiar & 3.0 & 3.0 & 3.0 & 3.0 \\
2. Otros costos para empleador & 14.1 & - & 14.1 & 14.1 \\
Vacaciones & 5.8 & - & 5.8 & 5.8 \\
Pagos complementariosi & 8.3 & - & 8.3 & 8.3 \\
D. Costo total $(A+C)$ & 147.6 & 129.3 & 152.9 & 152.9 \\
C/D (\%) & 32.2 & 22.7 & 34.6 & 34.6 \\
\hline
\end{tabular}


México

\begin{tabular}{|l|c|c|c|c|}
\hline & 1980 & 1990 & 1994 & 1998 \\
& Permanentes & Permanentes & Permanentes & Permanentes \\
\hline A. Remuneración bruta & 100.0 & 100.0 & 100.0 & 100.0 \\
Remuneración neta & 105.9 & 105.9 & 105.9 & 105.9 \\
B.Aportes del trabajador & 5.1 & 5.1 & 5.1 & 5.1 \\
Pensiones & 2.1 & 2.1 & 2.1 & 2.1 \\
Saludk & 3.0 & 3.0 & 3.0 & 3.0 \\
C. Contribuciones empleador & 40.6 & 46.8 & 48.7 & 48.8 \\
1. Contribuciones & 19.0 & 25.2 & 27.1 & 27.2 \\
Jubilación & 3.8 & 4.2 & 5.7 & 5.8 \\
Saludk & 5.6 & 8.4 & 8.8 & 8.8 \\
Guardería & 1.0 & 1.0 & 1.0 & 1.0 \\
Retiro & - & 2.0 & 2.0 & 2.0 \\
Accidentes & 2.6 & 2.6 & 2.6 & 2.6 \\
Vivienda & 5.0 & 5.0 & 5.0 & 5.0 \\
Impuesto a remuneración & 1.0 & - & - & - \\
Impuesto a nómina & - & 2.0 & 2.0 & 2.0 \\
2. Otros costos para empleador & 21.6 & 21.6 & 21.6 & 21.6 \\
Pagos complementarios & 11.0 & 11.0 & 11.0 & 11.0 \\
Vacaciones & 10.6 & 10.6 & 10.6 & 10.6 \\
D. Costo total $(A+C$ ) & 140.6 & 146.8 & 148.7 & 148.8 \\
C/D (\%) & 28.9 & 31.9 & 32.8 & 32.8 \\
\hline
\end{tabular}

Perú

\begin{tabular}{|l|c|c|c|}
\hline & 1990 & 1994 & 1998 \\
& Permanentes & Permanentes & Permanentes \\
\hline A.Salario bruto & 100.0 & 100.0 & 100.0 \\
Remuneración neta & 113.0 & 100.0 & 108.4 \\
B. Aportes del trabajador & 6.0 & 19.0 & 11.4 \\
Pensiones & 3.0 & 16.0 & 11.4 \\
Salud & 3.0 & 3.0 & - \\
C. Contribuciones del empleador & 66.8 & 62.9 & 65.6 \\
1. Contribuciones & 36.8 & 32.9 & 35.85 \\
Jubilación & 6.0 & - & - \\
Salud & 6.0 & 6.0 & 9.0 \\
Accidentes & 3.0 & 4.0 & 4.0 \\
Vivienda & 6.0 & 6.0 & 5.0 \\
SENATI (formación) & 1.5 & 1.2 & 0.75 \\
CTS (despidos) & 8.3 & 9.7 & 9.7 \\
Asignaciones familiares & 6.0 & 6.0 & 7.4 \\
2. Otros costos para el empleador & 30.0 & 30.0 & 29.7 \\
Vacaciones & 11.0 & 11.0 & 9.9 \\
Pagos complementarios & 19.0 & 19.0 & 19.8 \\
D. Costo total (A+C) & 166.8 & 162.9 & 165.6 \\
C/D (\%) & 40.0 & 38.6 & 39.6 \\
\hline
\end{tabular}

Fuente: Elaboración de la OIT sobre la base de información oficial.

a Las contribuciones del empleador para jubilación, obras sociales, asignaciones familiares y fondo de desempleo se redujeron en 1994 en $30 \%$ en Buenos Aires y en $80 \%$ en las provincias más pobres. Se estima una reducción promedio de $40 \%$. 
b Remuneración neta = remuneración bruta - aportes trabajador + ingresos complementarios

c Salud, incluido el Instituto Nacional de Servicios Sociales para Jubilados y Pensionados (INSSJ y P).

d Indemnización por despido. Para 1980 y 1990 se asume la tasa de 1994.

e Corresponde a gratificaciones o sueldos extraordinarios.

f $\mathrm{Ce}=$ contribuciones y otros costos para el empleador; $\mathrm{Ct}=$ costos para el trabajador.

g Promedio, tasa máxima: $3,9 \%$.

$\mathrm{h}$ Participación en beneficios del trabajador con ingreso medio equivalente a 2 salarios minimos.

i Incluye retroactividad de la cesantía.

j Corresponde a gratificaciones o sueldos extraordinarios.

k Instituto Mexicano de la Seguridad Social: sector privado.

I Obrero industrial afiliado a una AFP.

m Promedio. Las tasas oscilan entre $1.0 \%$ y $12.2 \%$.

\section{Costo laboral no salarial de los trabajadores con contrato temporal y sin contrato}

En tres de los seis países considerados (Chile, México y Perú), ${ }^{3}$ las alícuotas que se aplican a los asalariados con contrato temporal promovido por la legislación vigente son las mismas que las del contrato indefinido, mientras que en los otros tres -Argentina, Brasil y Colombiason diferentes. En Argentina, el costo laboral no salarial de estos trabajadores representó, en promedio, el $30.9 \%$ del salario bruto (14 puntos porcentuales menos que para un asalariado con contrato indefinido y cerca de 15 puntos menos que el vigente en 1990, cuando no existían contratos temporales promovidos). En Brasil, se estima que el costo laboral no salarial de un trabajador con contrato de duración definida representa el $37.2 \%$ del salario bruto, 21 puntos porcentuales menos que el de un trabajador permanente. En Colombia, el costo laboral no salarial de un asalariado temporal aumentó del $29.2 \%$ del salario bruto en 1988 (antes de la Ley 50) a un 52.9\% en la actualidad, alcanzando un nivel similar al del asalariado con contrato indefinido.

Vemos así que, salvo en Colombia, el costo no salarial de los asalariados temporales se ha mantenido o reducido, lo que junto al hecho de que perciben un salario inferior al del asalariado permanente, debiera generar una mayor demanda de este tipo de trabajadores. Si bien ello ha ocurrido llama la atención que no haya aumentado aún más la demanda de trabajadores no registrados, que perciben un salario menor

3 Obviamente, las cargas correspondientes a salarios diferidos, tiempo de servicios, indemnización por despido, etc., son proporcionales al tiempo de duración del contrato. 
que el del asalariado temporal y cuyo empleador no paga contribuciones sociales. ${ }^{4}$ Como señala Szretter (1999), la utilización de trabajadores no registrados podría formar parte de una estrategia más general de evasión de impuestos por parte de algunas empresas.

En suma, en los países considerados - salvo Brasil y Chile - las contribuciones laborales totales, estimadas como porcentaje del salario bruto, se han modificado. En Argentina disminuyeron, mientras que en Colombia, México y Perú han aumentado ligeramente. A su vez, en Chile, Colombia y Perú no hay diferencia entre los costos laborales no salariales de los trabajadores permanentes y los temporales. En Argentina y Brasil los asalariados temporales están sujetos a menores contribuciones patronales. En Argentina esta diferencia la establece la legislación vigente, mientras que en Brasil deriva de la práctica. Colombia presenta una situación singular, ya que si bien las alícuotas son similares para ambos tipos de contratos, no lo era así en 1988. La Ley 50 de 1990 encareció el costo relativo de la contratación temporal.

\section{APERTURA COMERCIAL Y PRECIOS RELATIVOS: SUS EFECTOS SOBRE LOS COSTOS LABORALES Y LA COMPETITIVIDAD}

Para el análisis que sigue se adopta la hipótesis de que habrá ganancias de competitividad cuando la productividad del trabajo aumente a tasas superiores a las del costo laboral. Sin embargo, cuando el cálculo del costo laboral se expresa en moneda nacional, para estimar su valor real es necesario decidir qué índice utilizar: el de precios al consumidor (IPC) o el de precios al productor (IPP). La decisión no resulta indiferente, ya que en los primeros años posteriores a la apertura comercial la evolución de uno y otro índice difiere. El IPC crece más rápido que el IPP y, por ende, el crecimiento del costo laboral real deflactado por el IPC es menor que el deflactado por el IPP. Como al trabajador le interesa defender el poder adquisitivo de su salario (es decir, con relación al IPC), tiende a considerar que el crecimiento de este índice es insuficiente. Por su parte, el empresario considera en su cálculo económico el crecimiento de los costos de la empresa, incluido el laboral, frente a la evolución de los precios de sus productos (IPP) y, por ello, percibe que el crecimiento del índice asi definido afecta su capacidad de competir. En esta situación,

4 Es posible, sin embargo, que en algunas empresas el empleador pague vacaciones y gratificaciones o sueldos extraordinarios. 
que se presenta en los años iniciales del proceso de apertura, ambos -trabajador y empleador- tienen apreciaciones opuestas, pero ambas justificadas, de la evolución del costo laboral real.

El cambio en los precios relativos IPC/IPP se debe a que la evolución de los precios al consumidor refleja una mayor influencia del crecimiento de los precios de los bienes y servicios no transables, los que suelen demorar en ajustarse porque están menos expuestos a la mayor competencia externa que se genera por la apertura, mientras que en la evolución de los precios al productor inciden más los precios de los bienes transables, que se ven afectados rápidamente por la apertura comercial $y$ tienden a alinearse con los precios internacionales.

Con posterioridad, y una vez que las empresas se ajustan a las condiciones del mercado, introducen mejoras en la organización de la producción y el trabajo, e invierten en tecnología y en capacitación de los trabajadores, el efecto de la competencia se traslada al sector de los bienes no transables. Los precios relativos comienzan entonces a estabilizarse y tiende a desaparecer progresivamente la diferente percepción de empresarios y trabajadores sobre la evolución del costo laboral.

En los tres paises cuyos procesos de apertura comenzaron en los años noventa, el IPC creció a tasas superiores al IPP, hasta 1993 en Argentina y Colombia y hasta 1994 en Perú (cuadro 2). A partir de esos años, la evolución de ambos índices ha tendido a alinearse y, en Argentina, incluso a mostrar un crecimiento del IPP mayor que el del IPC.

\section{CUADRO 2}

Argentina, Colombia y Perú:

Variación anual del índice de precios al consumidor (IPC) y al productor (IPP)

\begin{tabular}{|l|r|r|r|r|r|r|r|r|}
\hline & 1990 & 1991 & 1992 & 1993 & 1994 & 1995 & 1996 & 1997 \\
\hline Argentina & & & & & & & & \\
IPC & 1344.0 & 84.0 & 17.6 & 7.4 & 3.9 & 1.6 & 0.1 & 0.3 \\
IPP & 798.0 & 56.7 & 3.2 & 0.1 & 5.8 & 6.0 & 2.1 & -0.9 \\
Colombia & & & & & & & & \\
IPC & 32.4 & 26.8 & 25.1 & 22.6 & 22.6 & 19.7 & 21.6 & 17.7 \\
IPP & 29.9 & 23.1 & 17.9 & 13.2 & 20.7 & 15.4 & 14.5 & 17.5 \\
Perú & & & & & & & & \\
IPC & 7650.0 & 139.0 & 56.7 & 39.5 & 15.4 & 10.2 & 11.8 & 6.5 \\
IPP & 6534.0 & 96.0 & 50.5 & 34.1 & 10.5 & 8.8 & 11.4 & 5.0 \\
\hline
\end{tabular}

Fuente: CEPAL. 
Los costos laborales reales (deflactados por el índice de precios al consumidor) aumentaron en 1990-1995 a un ritmo inferior al de la productividad, excepto en Chile (cuadro 3). Se registraron ganancias de competitividad de alrededor del $10.2 \%$ anual en Argentina, 3.4\% en Brasil, $4.8 \%$ en México y $0.6 \%$ en el Perú. Al desagregar el costo laboral entre salarios y costo laboral no salarial se observa que el crecimiento de ambos componentes crece de manera similar en Brasil y Chile ${ }^{5}$ pero que en Argentina el costo laboral no salarial se expande menos que los salarios y que lo contrario ocurre en México y Perú.

\section{CUADRO 3}

Argentina, Brasil, Chile, México y Perú: Evolución de la competitividad laboral en el sector manufacturero, 1990-1995

(Valores en moneda nacional deflactados por IPC y tasas de crecimiento anuales)

\begin{tabular}{|c|c|c|c|c|c|}
\hline \multirow[t]{2}{*}{ Países } & \multicolumn{3}{|c|}{ Costo laboral real } & \multirow{2}{*}{$\begin{array}{l}\text { Produc- } \\
\text { tividad }\end{array}$} & \multirow{2}{*}{$\begin{array}{l}\text { Competi- } \\
\text { tividad }\end{array}$} \\
\hline & Salario & Costo no salarial & Total & & \\
\hline \multicolumn{6}{|l|}{ Argentina (pesos) } \\
\hline 1990 & 0.95 & 0.60 & 1.55 & & \\
\hline 1995 & 0.94 & 0.46 & 1.40 & & \\
\hline Variación anual & - & -5.2 & -2.0 & 8.0 & 10.2 \\
\hline Brasil (reales) & & & & & \\
\hline 1990 & & & & & \\
\hline 1995 & & & & & \\
\hline Variación anual & 2.9 & 2.9 & 2.9 & 6.4 & 3.4 \\
\hline \multicolumn{6}{|l|}{ Chile (pesos) } \\
\hline 1990 & 5.65 & 2.52 & 8.17 & & \\
\hline 1995 & 6.98 & 3.10 & 10.08 & & \\
\hline Variación anual & 4.3 & 4.2 & 4.3 & 3.6 & -0.7 \\
\hline \multicolumn{6}{|l|}{ México (pesos) } \\
\hline 1990 & 4.98 & 2.33 & 7.31 & & \\
\hline 1995 & 5.21 & 2.56 & 7.77 & & \\
\hline Variación anual & 0.9 & 1.9 & 1.2 & 6.1 & 4.8 \\
\hline \multicolumn{6}{|l|}{ Perú (nuevos soles) } \\
\hline 1990 & 0.21 & 0.12 & 0.33 & & \\
\hline 1995 & 0.26 & 0.16 & 0.42 & & \\
\hline Variación anual & 4.4 & 5.9 & 5.1 & 5.7 & 0.6 \\
\hline
\end{tabular}

Fuente: Elaboración de la OIT.

5 Cabe recordar que en Chile la reducción de los costos laborales no salariales se registró a comienzos de los ochenta. 
No obstante, dada la percepción diferente, ya señalada, que se produce entre trabajadores y empleadores, es necesario analizar también la evolución de los costos laborales en relación con el IPP. Como se observa en el cuadro 4, el costo laboral real aumenta significativamente más si se le deflacta por el IPP que si se lo deflacta por el IPC. En Argentina aumenta en $8.7 \%$ anual en el primer caso, mientras que si se deflacta por el IPC el costo se reduce en $2.0 \%$ anual (cuadro 3). En México y Brasil el costo laboral a precios de productor aumenta 4 veces más que a precios al consumidor, en Perú 3 veces y en Chile 1.6 veces. Como resultado, desde la perspectiva del empresario se registran pérdidas de competitividad en todos los países, excepto en México, situación muy diferente a la que se observa cuando se considera el IPC (cuadro 4) en la que todos los paises, excepto Chile, mejoran su competitividad.

Lo anterior deriva del cambio en los precios relativos como consecuencia de políticas macroeconómicas: por un lado, la apertura comercial que trae consigo mayores recursos provenientes del exterior $y$, por otro, una política de estabilización que utiliza la política cambiaria como ancla. Además, la expansión de exportaciones que acompaña a la apertu$\mathrm{ra}$, principalmente de productos primarios, contribuye también a deprimir el tipo de cambio. Todo ello afecta más rápidamente a los precios de los sectores transables (los más relevantes para el productor) que a los no transables (que tienen mayor importancia para los trabajadores en cuanto consumidores). Por lo tanto, la evolución de los costos e ingresos laborales es percibida de manera diferente por los involucrados, mientras que el origen del comportamiento diferenciado se encuentra más allá del ámbito laboral.

\section{CUADRO 4}

Argentina, Brasil, Chile, México y Perú: Evolución de la competitividad laboral en el sector manufacturero, 1990-1995

(Tasas de crecimiento anual, en moneda nacional deflactada por el IPP)

\begin{tabular}{|l|c|c|c|}
\hline Paises & Costo laboral real & Productividad & Competitividad \\
\hline Argentina & 8.7 & 8.0 & -0.6 \\
Brasil & 12.5 & 6.4 & -5.4 \\
Chile & 6.9 & 3.6 & -3.1 \\
México & 4.3 & 6.1 & 1.7 \\
Perú & 17.2 & 5.7 & -9.8 \\
\hline
\end{tabular}

Fuente: Elaboración de la OIT. 


\section{ESTRUCTURA DEL EMPLEO Y COSTOS LABORALES EN 1990- 1997}

En esta sección, por limitaciones de información sobre los costos laborales por modalidades de contratación, se considera solo a cuatro países: Argentina, Chile, Colombia y Perú. Se comparan aquí los costos laborales por hora de los trabajadores permanentes, temporales y sin contrato, y posteriormente se calcula el costo laboral medio que resulta de la suma ponderada de los costos de estos tres tipos de trabajadores. Se determina asimismo la reducción que se produce respecto de una situación en que no hubiera habido modificaciones a la legislación laboral ni cambios en la estructura del empleo manufacturero por modalidad de contratación. Considerando el crecimiento de la productividad industrial en el período analizado, se calculan las ganancias y pérdidas de competitividad con cambios y sin cambios en la estructura del empleo. Los costos se miden en dólares corrientes, lo que permite analizar el efecto del rezago cambiario en ellos y en la competitividad, y se estima por último la evolución que hubiera tenido la competitividad si no hubiera existido rezago cambiario.

\section{La estructura del empleo asalariado en el sector industrial}

En el período analizado, la participación de los asalariados con contratos indefinidos en la industria manufacturera bajó, excepto en Colombia, y la de los asalariados con contrato temporal subió y, salvo en Colombia, subió también la de los sin contrato (cuadro 5).

En Argentina la participación de los asalariados con contrato por tiempo indefinido se redujo en 5.6 puntos porcentuales entre 1991 y 1998, y aumentó en casi 1.5 puntos la de los temporales y en algo más de 4 puntos la de los trabajadores no registrados. En Perú, la participación de los asalariados con contrato por tiempo indefinido disminuyó alrededor de 30 puntos porcentuales entre 1989 y 1997 y creció más de 20 puntos la de los temporales y 9 puntos la de los asalariados sin contrato. Por el contrario, en Colombia la participación de los asalariados con contrato indefinido aumentó en 2.7 puntos porcentuales entre 1988 y 1996, la de los asalariados no registrados disminuyó 3 puntos y la de los temporales remontó solo 0.3 puntos. 


\section{CUADRO 5}

Argentina, Brasil, Chile, Colombia y Perú:

Estructura del empleo asalariado en la industria según la modalidad de contratación

\begin{tabular}{|c|c|c|c|}
\hline & $\begin{array}{c}\text { Con contrato } \\
\text { indefinido }\end{array}$ & $\begin{array}{c}\text { Con contrato } \\
\text { temporal }\end{array}$ & Sin contrato \\
\hline $\begin{array}{c}\text { Argentina } \\
1991 \\
1998\end{array}$ & 67.6 & 2.2 & 30.2 \\
Brasil & 62.0 & 3.6 & 34.4 \\
1991 & $67.9^{\mathrm{a}}$ & & 32.1 \\
1996 & $65.4^{\mathrm{a}}$ & & 34.6 \\
Chile & & & \\
1990 & 74.7 & 9.6 & 15.5 \\
1996 & 62.7 & 7.4 & 29.9 \\
Colombia & 65.4 & 7.7 & 26.9 \\
1988 & 55.0 & 16.1 & 28.9 \\
1996 & 25.1 & 37.5 & 37.4 \\
Perú & & & \\
1989 & & & \\
1997 & & & \\
\hline
\end{tabular}

Fuente: Elaboración propia con base en estudios nacionales.

a Trabajadores "con cartera"; incluye trabajadores con contrato indefinido y con contrato temporal.

Como resultado de los cambios en la estructura del empleo, en todos los países considerados, excepto en Colombia, se hizo más precario el empleo asalariado en la industria manufacturera (especialmente en Perú).

\section{Costos laborales por modalidad de contratación y costo laboral medio}

Conviene, en primer lugar, examinar el costo laboral de los asalariados temporales y no registrados, ya que su nivel menor que el de los asalariados permanentes debería generar el efecto esperado de aumentar el empleo sin aumentar la desprotección o la precarización. Para ello se examinan las contribuciones patronales que deben efectuarse para los trabajadores con contratos temporales, y las diferencias de salarios entre trabajadores con contrato permanente, con contrato temporal y sin contrato. 
A pesar de que, como se señaló, las leyes no exoneran de contribución patronal para los asalariados temporales (excepto en Argentina), dicha contribución se reduce en términos absolutos porque los salarios brutos de estos trabajadores son menores que los de los asalariados permanentes. En 1966 la industria manufacturera pagaba a los temporales el $60 \%$ de lo pagado a los permanentes ${ }^{6}$ en Argentina y Chile, y el $64 \%$ en Colombia y Perú. ${ }^{7} \mathrm{Al}$ ser las contribuciones laborales del empleador el mismo porcentaje del salario bruto, el costo laboral por hora trabajada de los asalariados temporales en la industria es menor que el de los asalariados permanentes en la misma proporción que el salario bruto ( $34 \%$ en Colombia y Perú, y $40 \%$ en Chile).

En Argentina, el costo laboral por hora trabajada de los asalariados temporales es inferior en $44 \%$ al de los asalariados permanentes. De esta diferencia, el $62 \%$ corresponde a salarios y el $38 \%$ a la exoneración de contribuciones patronales (cuadro 6).

Considerando las diferencias salariales señaladas para los cuatro paises indicados (no se dispone de información suficiente en el caso de Brasil) y la exoneración parcial de las contribuciones patronales en Argentina, se puede estimar las diferencias en el costo por hora según modalidad de contratación (cuadros 6 y 7). El costo de contratar a un asalariado temporal sería entre un 56 y un $65 \%$ del costo de contratar a un trabajador permanente.

El efecto potencial de la reducción del costo de contratación de un trabajador temporal sobre los costos laborales medios de las empresas depende del porcentaje del total de trabajadores que la ley permite cubrir con trabajadores temporales bajo modalidades promovidas por las legislación. En Argentina, este porcentaje no puede superar el $30 \%$ en empresas con más de 25 trabajadores y el $50 \%$ en empresas entre 6 y 25 trabajadores, y puede llegar a la totalidad de los trabajadores en empresas con menos de 6 trabajadores ocupados. En Colombia, Chile y Perú la ley no establece límite a esa contratación.

6 Otros estudios señalan que el salario medio de los trabajadores temporales representa el $81.5 \%$ del de los permanentes.

7 Se refiere a salarios medios de cada grupo. La diferencia se reduce a medida que aumentan los años de educación. El salario medio de los trabajadores con estudios universitarios no difiere significativamente si tienen contratos temporales o indefinidos. 


\section{CUADRO 6}

Argentina, Brasil, Chile, Colombia, Perú: Costo laboral por hora de los asalariados permanentes y temporales en la industria manufacturera

(Dólares corrientes)

\begin{tabular}{|c|c|c|c|c|c|c|c|}
\hline \multirow[t]{2}{*}{ Países y años } & \multicolumn{3}{|c|}{ Permanentes } & \multicolumn{3}{|c|}{ Temporales (contrato de 1 año) } & \multirow{2}{*}{$\begin{array}{c}\text { Costo de } \\
\text { temporales } \\
\text { costo de } \\
\text { permanentes }\end{array}$} \\
\hline & Salario & $\begin{array}{c}\text { Costo laboral } \\
\text { no salarial }\end{array}$ & Costo laboral & Salario & $\begin{array}{c}\text { Costo Laboral } \\
\text { no salarial }\end{array}$ & Costo labora & \\
\hline Argentina, 1998 & 4.57 & 1.96 & 6.53 & 2.76 & 0.87 & 3.63 & 0.56 \\
\hline Brasil, 1996 & 3.74 & 2.18 & 5.92 & .. & & & \\
\hline Chile, 1996 & 2.37 & 0.91 & 3.28 & 1.43 & 0.54 & 1.97 & 0.60 \\
\hline Colombia, 1996 & 1.44 & 0.76 & 2.20 & 0.91 & 0.49 & 1.40 & 0.64 \\
\hline Perú, 1997 & 1.29 & 0.83 & 2.12 & 0.83 & 0.54 & 1.37 & 0.65 \\
\hline
\end{tabular}

Fuente: OIT. Elaboración a partir de datos oficiales de los países y estudios de casos.

\section{CUADRO 7}

Argentina, Brasil, Chile, Colombia y Perú:

Costo laboral de trabajadores con contrato y sin contrato, 1996

(Dólares corrientes)

\begin{tabular}{|l|cc|c|cc|}
\hline \multirow{2}{*}{ Países } & \multicolumn{2}{|c|}{ con contrato } & & \multicolumn{2}{c|}{$\begin{array}{c}\text { Costo sin contrato/costo } \\
\text { Con contrato }\end{array}$} \\
\cline { 2 - 3 } & Permanentes & Temporales & Sin contrato & & Temporales Permanentes \\
\hline Argentina, 1998 & 6.53 & 3.63 & 3.01 & 0.83 & 0.46 \\
Brasil, 1996 & 5.92 & $\ldots$ & 1.26 & $\ldots$ & 0.21 \\
Chile, 1996 & 3.28 & 1.97 & 1.37 & 0.70 & 0.42 \\
Colombia, 1996 & 2.20 & 1.40 & 0.90 & 0.64 & 0.41 \\
Perú, 1997 & 2.12 & 1.32 & 1.01 & 0.76 & 0.48 \\
\hline
\end{tabular}

Fuente: Elaboración propia basada en estudios nacionales.

Por lo tanto, en una empresa de tamaño medio que pueda contratar hasta $30 \%$ de trabajadores temporales, la introducción de modalidades de contratación promovidas por la legislación permitiría reducir el costo laboral medio en alrededor del $13 \%$ en Argentina, el $34 \%$ en Colombia, el $43 \%$ en Chile y el $38 \%$ en Perú. Cabe señalar, sin embargo, que en Chile la reforma fue introducida en 1978 , por lo que el efecto sobre la reducción del costo laboral se registró con anterioridad al período analizado. 


\section{Costo laboral de los trabajadores asalariados no registrados}

El costo laboral no salarial de los trabajadores no registrados es menor que el de los trabajadores con contratos, debido tanto a que se paga solo una parte de las contribuciones legales, como a que los salarios brutos son menores.

En relación con las contribuciones a cargo del empleador, se considera que estos trabajadores perciben los salarios diferidos (como vacaciones y gratificaciones), que posiblemente son contabilizados como gastos generales de la empresa. Existen dudas sobre si los beneficios por vacaciones y sueldos extraordinarios son similares para el trabajador no registrado y registrado. Szretter (1999), estima que el asalariado no registrado recibe, en promedio, la mitad de los salarios diferidos que el asalariado con contrato temporal, lo que representaría el $6.6 \%$ del salario bruto (en comparación con $13.2 \%$ en el caso de los temporales). No obstante, para los fines de este trabajo hemos supuesto que los asalariados sin contrato perciben por concepto de vacaciones e ingresos complementarios lo mismo que los asalariados con contratos temporales, lo que representaría el $13.2 \%$ del salario bruto en Argentina, el $11.3 \%$ en Brasil, el $14.1 \%$ en Colombia, el $27.1 \%$ en Chile y el $29.7 \%$ en Perú. ${ }^{8}$

El salario bruto del trabajador no registrado es menor que el del asalariado con contrato indefinido y con contrato temporal. En la hipótesis planteada más arriba, el salario del trabajador sin contrato en el último año del período analizado representaría en Argentina el $94 \%$ del salario del trabajador temporal y el $58.3 \%$ del permanente, en Chile el $91 \%$ y $53 \%$, respectivamente, en Colombia el $94 \%$ y $62 \%$, y en Perú sería similar al del asalariado temporal. En Brasil (donde no se dispone de información sobre salario medio de los asalariados temporales), el salario del trabajador "sin cartera" representaba en 1996 el 30\% del que percibía el trabajador "con cartera".

De allí que el costo de emplear a un trabajador sin contrato sería inferior al de emplear a uno con contrato temporal (17\% en Argentina, 30\%

8 La mayor proporción en Chile y Perú se debe a que se supone que, al igual que el resto de los asalariados, el trabajador sin contrato también percibe dos salarios extraordinarios por año en Perú, y gratificaciones anuales equivalentes al $25 \%$ del salario bruto mensual en Chile. 
en Chile, $36 \%$ en Colombia y $24 \%$ en Perú). Y mucho menor que el de ocupar a un asalariado permanente (54\% en Argentina, $58 \%$ en Chile, $59 \%$ en Colombia, $52 \%$ en Perú y $79 \%$ en Brasil).

\section{Costo laboral medio}

Basándose en los costos laborales por modalidad de contratación y la estructura del empleo en la industria manufacturera (cuadro 2), puede calcularse el costo laboral medio por hora en el período analizado. Como resultado, se observa que en 1997 ascendió a 5.12 dólares corrientes en Argentina, 3.67 en Brasil, 3.03 en Chile, 1.92 en Colombia y 1.73 en Perú (cuadro 8).

\section{CUADRO 8}

Argentina, Brasil, Chile, Colombia y Perú: Costo laboral por hora en la industria manufacturera (Dólares corrientes)

\begin{tabular}{|c|c|c|c|c|c|c|c|c|c|c|c|c|c|c|c|}
\hline & \multicolumn{3}{|c|}{ Argentina } & \multicolumn{3}{|c|}{ Brasil } & \multicolumn{3}{|c|}{ Chile } & \multicolumn{3}{|c|}{ Colombia } & \multicolumn{3}{|c|}{ Perú } \\
\hline & Perm. ${ }^{a}$ & Prom. & Diferen. & Perm. & Prom. & Diferen. & Perm. & Prom. & Diferen. & Perm. & Prom. & Diferen. & Perm. & Prom. & Diferen. \\
\hline 1988 & .. & $\ldots$ & -. & & & 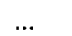 & 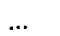 & $\ldots$ & - & 1.1 & 0.9 & $18 \%$ & & & - \\
\hline 1989 & $\ldots$ & $\ldots$ & - & 2.37 & 1.84 & $22 \%$ & $\ldots$ & $\ldots$ & - & $\ldots$ & $\ldots$ & - & 0.96 & 0.81 & $16 \%$ \\
\hline 1990 & & & - & 2.25 & 1.73 & $23 \%$ & 2.54 & 2.2 & $13 \%$ & $\ldots$ & $\ldots$ & - & & $\ldots$ & - \\
\hline 1991 & 4.55 & 3.64 & $20 \%$ & 2.32 & 1.77 & $24 \%$ & & & . & $\ldots$ & $\ldots$ & - & & $\ldots$ & - \\
\hline 1996 & 6.33 & 5.04 & $20 \%$ & 5.92 & 4.2 & $29 \%$ & 3.4 & 2.95 & $13 \%$ & 2.1 & 1.7 & $19 \%$ & 2.2 & $\ldots$ & - \\
\hline 1997 & 6.31 & 5.12 & $19 \%$ & 5.17 & 3.67 & $29 \%$ & 3.49 & 3.03 & $13 \%$ & 2.37 & 1.92 & $19 \%$ & 2.12 & 1.73 & $18 \%$ \\
\hline
\end{tabular}

Fuente: Estudios de países efectuados por la OIT.

a Costo laboral por hora del trabajador con contrato indefinido.

b Costo laboral promedio por hora del total de trabajadores de la industria.

Dicho costo medio es entre 13 y $29 \%$ más bajo que el que resultaría si los trabajadores tuvieran contratos indefinidos. ${ }^{9}$ Como se observa en el cuadro 8 , en Brasil la diferencia sería de $29 \%$, en Argentina y Colombia de $19 \%$ y en Perú de $18 \%$. Si bien en Argentina el porcentaje se redujo ligeramente en los últimos siete años, en Colombia se mantiene y en Perú aumenta. Este diferente comportamiento se explica porque en Ar-

9 Se trata de una reducción máxima potencial, ya que no es factible que en empresas (públicas o privadas) todos los trabajadores cuenten con contratos de tiempo indefinido. 
gentina, aun cuando ha aumentado la participación de los trabajadores sin contrato y con contrato temporal, se ha reducido la diferencia salarial entre los trabajadores no registrados y los con contrato indefinido (en $0.70 \%$ en 1991 y $0.85 \%$ en 1997$).{ }^{10}$ En Perú el comportamiento observado se debe a que ha aumentado tanto la participación de trabajadores con contrato temporal y sin contrato como las diferencias salariales.

El costo laboral medio estimado no solo es inferior al que se habría registrado si todos los trabajadores hubieran tenido contratos indefinidos, sino que también es inferior (salvo en Colombia) al que resultaría si se hubiera mantenido la estructura del empleo que existía en el año inicial del período analizado. En Argentina el costo laboral en 1997 habría sido de 5.32 dólares en lugar de 5.12 (3.8\% superior); en Brasil de 3.77 dólares en lugar de 3.67 (2.7\% superior). Solo en Colombia habría sido inferior: 1.89 dólares en vez de 1.92 (1.6\% menor). Este ha sido el principal efecto económico de la flexibilización de las modalidades de contratación. En un contexto en que las tasas de cambio se utilizan como ancla de la política de estabilización, esta flexibilización debería facilitar el ajuste del mercado de trabajo y permitir que, para una productividad dada, la reducción del costo laboral medio se traduzca en ganancias de competitividad.

\section{COSTO LABORAL, PRODUCTIVIDAD Y COMPETITIVIDAD}

\section{Costo laboral y competitividad}

En los años noventa el costo laboral medio en la industria manufacturera (en dólares corrientes) aumentó en un 5.9\% anual en Argentina, $4.7 \%$ en Chile, $9.0 \%$ en Brasil, $8.8 \%$ en Colombia y $9.9 \%$ en Perú (cuadro 9).

10 La evolución de las diferencias salariales en Argentina debe ser tomada con cautela, ya que es posible que entre los trabajadores no registrados se incluya a profesionales que prestan servicios a empresas sin estar registrados en la planiIla. Dichos profesionales usualmente tienen salarios más altos que el promedio y un crecimiento mayor. 


\section{CUADRO 9 \\ Algunos países: \\ Evolución del costo laboral medio, la productividad y la competitividad}

(Tasas anuales)

\begin{tabular}{|c|c|c|c|c|c|}
\hline \multirow[t]{2}{*}{ Países y años } & \multicolumn{2}{|c|}{ Costo } & \multirow[t]{2}{*}{ Productividad } & \multicolumn{2}{|c|}{ Competitividada } \\
\hline & Con cambio & Sin cambiob & & Con cambio ${ }^{\mathrm{b}}$ & Sin cambio \\
\hline EE.UU., 1990-1996 & \multirow{2}{*}{\multicolumn{2}{|c|}{$\begin{array}{r}2.9 \\
14 ?\end{array}$}} & 4.4 & \multicolumn{2}{|c|}{1.5} \\
\hline Rep. de Corea, 1990-1996 & & & 12.0 & \multicolumn{2}{|c|}{-1.9} \\
\hline Alemania, 1990-1996 & \multicolumn{2}{|c|}{$\begin{array}{r}14.2 \\
2.1\end{array}$} & 6.2 & \multicolumn{2}{|c|}{4.0} \\
\hline Argentina, 1991-1997 & 5.9 & 6.5 & 9.4 & 3.3 & 2.7 \\
\hline Brasil, 1989-1997 & 9.0 & 9.4 & 5.3 & -3.4 & -3.7 \\
\hline Chile, $1990-1997$ & 4.7 & $\ldots$ & 7.8 & 3.0 & $\ldots$ \\
\hline Colombia, 1988-1997 & 8.8 & 8.6 & 3.5 & -4.9 & -4.7 \\
\hline Perú, 1989-1997 & 9.9 & 12.2 & 3.4 & -5.9 & -7.8 \\
\hline
\end{tabular}

Fuente: Elaboración de la OIT.

a Se calcula aplicando la fórmula

$$
c=\frac{(1+q)}{(1+c l)}-1
$$

donde

$c=$ variación anual de la competitividad

$q=$ variación anual de la productividad.

$\mathrm{cl}=$ variación anual del costo laboral.

b En la estructura del empleo por modalidad de contrato.

Este aumento significativo (vinculado en gran medida con el rezago cambiario que se registró en el decenio), fue inferior al crecimiento de la productividad ${ }^{11}$ en Argentina ( $9.4 \%$ anual) y Chile (7.8\%) y superior en Colombia (3.5\%), Brasil (5.3\%) y Perú (3.4\%). Como consecuencia, la competitividad industrial subió alrededor de 3.0\% anual en Argentina y en Chile, mientras que se contrajo en $3.4 \%$ anual en Brasil, $4.9 \%$ en Colombia y $5.9 \%$ en Perú.

El aumento de la competitividad en Argentina y Chile fue superior al registrado en Estados Unidos y la República de Corea en 1990-1996, debido fundamentalmente al rápido aumento de la productividad en los dos países latinoamericanos. Por el contrario, la pérdida de competitividad en Brasil, Colombia y Perú (superior incluso a la registrada en la República de Corea) se debió tanto al acelerado aumento del costo laboral como al modesto crecimiento de la productividad.

11 Valor bruto de la producción por ocupado, expresado en dólares corrientes. 
¿Cuál hubiera sido la evolución de la competitividad si en 1997 se hubiese mantenido en cada país la estructura del empleo asalariado del primer año del período analizado? Como se señaló, el costo laboral en Argentina hubiera sido 3.8\% superior al observado, en Brasil $2.7 \%$ superior, en Perú $15 \%$ superior y en Colombia $1.6 \%$ inferior. Esto significa que el costo laboral por hora hubiese aumentado anualmente más de lo que aumentó con el cambio de estructura en Argentina, Brasil y Perú, y ligeramente menos en Colombia. Así, la competitividad industrial en Argentina se hubiera acrecentado en 0.5 puntos porcentuales menos de lo que se acrecentó y la pérdida de competitividad en Brasil y Perú en 0.2 y 1.9 puntos respectivamente, mientras que en Colombia la pérdida hubiese sido 0.2 puntos porcentuales inferior a la observada (cuadro 9).

La introducción de modalidades precarias de contratación posibilitó la reducción del costo laboral, tanto por el menor costo no salarial en Argentina, como por los salarios más bajos en todos los países considerados. Con esto se pudo elevar la competitividad de Argentina, a pesar del tipo de cambio fijo, y compensar en parte las pérdidas de competitividad generadas por el lento crecimiento de la productividad y el rezago cambiario en Brasil, Colombia y Perú.

El aumento del costo laboral en dólares se debió a la expansión de los salarios nominales en un contexto de rezago cambiario. A su vez, el incremento de la productividad se sustentó principalmente en la reducción del nivel de empleo. ${ }^{12}$ Como resultado, la evolución de la competitividad ha estado determinada por la influencia de los cambios en la estructura del empleo y de las políticas cambiarias sobre los costos laborales y por el efecto de la reducción en los niveles de empleo sobre la productividad.

\section{Costo laboral y tipo de cambio efectivo}

En el periodo de análisis, la mayoría de los países considerados experimentó una sobrevaluación de la moneda nacional y un rezago cambiario, debido tanto a la afluencia de capitales externos como al uso del tipo de cambio como ancla en la política de estabilización. Pero en otros la política cambiaria aplicada vinculó la moneda local a la evolu-

12 Véase Amadeo, Camargo, Frenkel y Hernández-Laos, 1999. 
ción de la relación entre la inflación interna y externa, por lo que el tipo de cambio mantuvo su paridad y subió a tasas similares o incluso superiores a las de inflación. En este último caso se produjo una subvaluación de la moneda nacional o una devaluación real.

Las ganancias reales de competitividad laboral se producirán cuando la tasa de crecimiento de la productividad del trabajo sea superior a la del costo laboral y además, sea suficiente para compensar el efecto del rezago del tipo de cambio.

Al incorporar al análisis los efectos generados por el rezago cambiario, utilizando el tipo de cambio efectivo determinado por el comportamiento de la moneda nacional frente a las monedas de los principales socios comerciales, la evolución de la competitividad calculada experimenta variaciones significativas (cuadro 9).

Veamos ahora la evolución de la competitividad en la industria manufacturera luego de corregir los atrasos o adelantos del tipo de cambio efectivo (cuadros 10 y 11).

\section{CUADRO 10}

Algunos países:

Evolución de la competitividad laboral en la industria manufacturera luego de una corrección cambiaria

\begin{tabular}{|l|c|c|c|c|}
\hline \multicolumn{1}{|c|}{ País } & $\begin{array}{c}\text { Productividad } \\
\text { (año base=100) }\end{array}$ & $\begin{array}{c}\text { Costo laboral } \\
\text { (año base=100) }\end{array}$ & $\begin{array}{c}\text { Tipo de cambio } \\
\text { efectivo } \\
\text { (año base=100) }\end{array}$ & $\begin{array}{c}\text { Variación } \\
\text { anual de la } \\
\text { competitividad }\end{array}$ \\
\hline EE.UU. (1990-1996) & 129.5 & 118.7 & 96.9 & 2.0 \\
Rep. de Corea (1990-1996) & 197.4 & 221.8 & 118.0 & -4.6 \\
Alemania (1990-1996) & 143.5 & 113.3 & 122.5 & 0.6 \\
Argentina (1991-1997) & 171.4 & 141.1 & 71.3 & 9.3 \\
Brasil (1989-1997) & 151.2 & 199.3 & 64.5 & 2.0 \\
Chile (1990-1997) & 169.2 & 137.9 & 87.2 & 5.0 \\
Colombia (1988-1997) & 136.3 & 213.6 & 64.7 & -0.2 \\
Perú (1989-1997) & 130.7 & 212.8 & 91.8 & -4.9 \\
\hline
\end{tabular}

Fuente: Cuadro 9 y CEPAL para el tipo de cambio efectivo.

a Se calcula aplicando la fórmula

$$
c=\left|\frac{(1+q)(1+t c)}{(1+c l)}\right|-1
$$

donde

$c$ es la variación anual de la competitividad, $q$ es la variación anual de la productividad, tc es la variación anual del tipo de cambio efectivo y cl es la variación anual del costo laboral. 
CUADRO 11

Algunos países: Variación de la competitividad del sector manufacturero

\begin{tabular}{|l|c|c|}
\hline \multicolumn{1}{|c|}{ Pais } & $\begin{array}{c}\text { Con rezago o } \\
\text { adelanto cambiario }\end{array}$ & $\begin{array}{c}\text { Sin rezago o } \\
\text { adelanto cambiario }\end{array}$ \\
\hline EE.UU. (1990-1996) & 1.5 & 2.0 \\
Rep. de Corea (1990-1996) & -1.9 & -4.6 \\
Alemania (1990-1996) & 4.0 & 0.6 \\
Argentina (1991-1997) & 3.3 & 9.3 \\
Brasil & -3.4 & 2.0 \\
Chile (1990-1997) & 3.0 & 5.0 \\
Colombia (1988-1997) & -4.9 & -0.2 \\
Perú (1989-1997) & -5.9 & -4.9 \\
\hline
\end{tabular}

Fuente: Cuadros 9 y 10.

Las ganancias de competitividad se redujeron y las pérdidas aumentaron en países como la República de Corea y Alemania, que devaluaron sus monedas más allá del nivel en el que se mantendria el equilibrio o la paridad con el valor de las monedas de sus principales socios comerciales. Por el contrario, en países como Argentina, Brasil, Chile, Colombia y Perú, que tenían una moneda sobrevaluada, la corrección cambiaria aumentó las mejoras de competitividad (Argentina y Chile) y disminuyó las pérdidas (Colombia y Perú) o las convirtió en ganancias (Brasil).

Examinando el comportamiento por país se observa que, durante el período analizado, la productividad en el sector manufacturero de Argentina, Brasil, Colombia, Chile y Perú aumentó significativamente, pero a ritmo inferior al del costo laboral en los casos de Brasil, Colombia y Perú (cuadro 9), registrándose una pérdida de competitividad de 3.4 , 4.9 y $5.9 \%$, respectivamente. Una evolución diferente se observó en Argentina y en Chile, donde el aumento de la productividad superó al del costo laboral medio, originando ganancias de competitividad del orden de 3.3 y $3.0 \%$, respectivamente. Si se introduce una corrección del tipo de cambio (cuadro 10), la ganancia de competitividad sería mayor en Argentina (9.3\% anual) y en Chile $(5.0 \%)$, las pérdidas serían menores en Colombia $(-0.2 \%)$ y Perú $(-4.9 \%)$ y se convertirian en ganancia en Brasil (2.0\%).

En cuanto a los paises de fuera de la región, se observa que en Alemania la ganancia de competitividad habría sido menor de no haberse producido una devaluación de su moneda, y en la República de Corea las pérdidas habrían sido mayores. En Estados Unidos, las ganancias de 
competitividad aparecen ligeramente mayores si se considera la evolución de la paridad del dólar frente a las monedas de sus principales socios comerciales.

En suma, el análisis hasta aquí realizado muestra que la capacidad competitiva de los países resulta tanto de las decisiones de empresarios y trabajadores en materia de costos laborales y productividad, como de las políticas macroeconómicas. Durante el período analizado, el rezago cambiario existente en muchos países de la región encareció el costo laboral nominal y disminuyó los retornos en moneda nacional de las exportaciones, generándose pérdidas de competitividad en la mayoría de ellos.

Como ya se señaló, en las políticas cambiarias seguidas han influido la afluencia de capitales externos de corto plazo a raíz de la apertura de los mercados, y la política de estabilización. La globalización de la economía habría tenido así, en el caso de los países analizados, no solo los conocidos efectos positivos, sino también un efecto cambiario que hasta ahora incide negativamente en la competitividad manufacturera. Además, dicha globalización desplaza el peso del ajuste interno hacia los costos, principalmente laborales, y la productividad. La evolución del costo laboral en los paises analizados incide sobre la competitividad, pero su incidencia depende de la evolución de la productividad y está determinada además por el efecto de las políticas macroeconómicas. A su vez, estos factores resultan ser, durante este período, más importantes que la evolución de los salarios y los gravámenes sobre los salarios para financiar las prestaciones sociales.

La incidencia de la política cambiaria sobre los costos laborales y la competitividad quedó claramente de manifiesto a raíz de la devaluación que introdujeron todos los países, excepto Argentina, para compensar los efectos de las maxidevaluaciones efectuadas en los países asiáticos en 1997.

\section{Costos laborales y competitividad en el contexto de la crisis del sudeste asiático}

Las medidas adoptadas por los paises del sudeste asiático para enfrentar la crisis que los afectó a partir del segundo semestre de 1997 obligó a las empresas latinoamericanas a desplegar un esfuerzo mayor para, 
por lo menos, mantener los niveles de competitividad relativa respecto de dichos paises.

Las devaluaciones introducidas en los países del sudeste asiático provocaron una disminución de los costos laborales en dólares entre el primer semestre de 1997 y el primero de 1998 en porcentajes que fueron de $24.8 \%$ en Tailandia, $28.1 \%$ en Filipinas, $33.1 \%$ en la República de Corea, $34.9 \%$ en Indonesia y $38.4 \%$ en Malasia. Esta reducción de los costos laborales se produjo en medio de una contracción generalizada de los salarios reales causada por la aceleración del ritmo inflacionario en todos estos paises. Por otra parte, la productividad media del trabajo en el sector manufacturero también se redujo debido a que el empleo no se alineó con la abrupta caída de la producción industrial durante el ajuste (OIT, 1998).

Como resultado de la evolución de los costos laborales y de la productividad, la competitividad del sector manufacturero aumentó significativamente en todos los países del sudeste asiático durante el primer semestre de 1998, comparado con igual período del año anterior, situándose sus ganancias de competitividad entre 40 y $60 \%$, salvo en Tailandia donde alcanzaron a $21.4 \%$.

Por lo tanto, la competitividad de los paises latinoamericanos en 1998 debería haberse elevado entre 20 y $60 \%$ solo para mantener los niveles de competitividad relativa previos a la crisis. Como era difícil, si no imposible, efectuar una nueva reducción del costo laboral de ese orden y como tampoco era posible aumentar la productividad en esa misma magnitud en el corto plazo, la única posibilidad fue la de redireccionar las políticas cambiarias: es decir, devaluar más la moneda nacional para lograr la consiguiente reducción de los costos expresados en dólares.

Entre el primer semestre de 1996 y el primero de 1997 -en los 12 meses previos a la crisis asiática- las ganancias de competitividad en el sector manufacturero fueron importantes en todos los paises analizados, excepto en Chile, donde ésta bajó $4.1 \%$ (gráfico 1). El incremento de la competitividad en esos 12 meses en Argentina (7.5\%), Brasil (6.1\%) y Perú (4.4) se debió al alto crecimiento de la producción por hora trabajada (entre $5.4 \%$ en Perú y $7.5 \%$ en Argentina y Brasil), en circunstancias de que el costo laboral subió $0.2 \%$ en Argentina y poco más de $1.0 \%$ en Brasil y Perú. En Colombia, el aumento de la competitividad $(6.2 \%)$ se debió exclusivamente a la reducción del costo 
laboral en dólares, que resultó de la devaluación del peso, ya que la productividad aumentó en solo $0.7 \%$.

A diferencia de lo observado anteriormente, la evolución de los costos laborales y de la productividad a partir de la crisis asiática -es decir, entre el primer semestre de 1997 y el primero de 1998- muestra que el costo laboral disminuyó en todos los países, excepto en Argentina, en porcentajes que oscilaron entre $0.4 \%$ en Brasil y $4.9 \%$ en Colombia, con reducciones intermedias de $1.9 \%$ en Chile y $4.3 \%$ en Perú (gráfico 2). Obviamente estas reducciones -en el marco de salarios reales que, salvo en Argentina y Perú, aumentaron debido a que el ajuste se estaba llevando a cabo sin elevar la inflación- estuvieron asociadas a la devaluación mayor (Chile, Colombia y Perú) o menor (Brasil) de las respectivas monedas nacionales en esos doce meses. Paralelamente a esta reducción del costo laboral en dólares, en todos los países, excepto en Perú, hubo aumentos de productividad (producción física por hora trabajada) de $3.9 \%$ en Brasil, $4 \%$ en Chile y $5.4 \%$ en Colombia. Todo esto hizo que la competitividad se elevara a una tasa de entre $4.3 \%$ en Brasil y $10.9 \%$ en Colombia (gráfico 2). En Perú, si bien el costo laboral en dólares bajó por efectos de la devaluación, la productividad se redujo en un 4\%, con lo cual la competitividad aumentó en solo 0.3\%. En Argentina, a pesar del aumento del costo laboral en dólares, la competitividad mejoró $(3.7 \%)$ merced al aumento de la productividad (6.8\%) que resultó tanto del crecimiento de la producción física como de una ligera reducción del empleo manufacturero.

En suma, los incrementos de productividad logrados en algunos países, gracias a la expansión de la producción industrial y a un menor nivel de empleo, así como las devaluaciones que se han introducido en otros países y que han contribuido a reducir el costo laboral en dólares, permitieron mejorar la competitividad en los 12 meses siguientes al comienzo de la crisis asiática. No obstante, esto no impidió que se produjese una pérdida de competitividad relativa ya que, como se señaló antes, en los países asiáticos el aumento de la competitividad fue mayor, más por la reducción de los costos laborales en dólares que por incrementos en la productividad. 


\section{GRÁFICO 1}

Argentina, Brasil, Chile, Colombia y Perú:

Variación anual del costo laboral, la productividad y

la competitividad en el sector manufacturero

(Primer semestre de 1996-primer semestre de 1997)

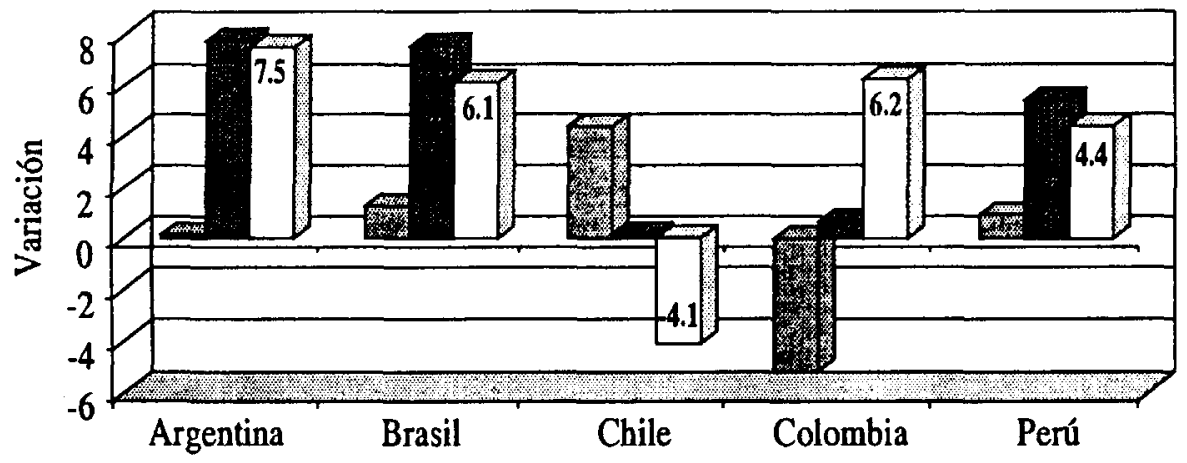

Costo laboral 97

Proctuctividad $97 \square$ Competitividad 97

\section{GRÁFICO 2}

Argentina, Brasil, Chile, Colombia y Perú:

Variación anual del costo laboral, la productividad y

la competitividad en el sector manufacturero

(Primer semestre de 1997-primer semestre de 1998)

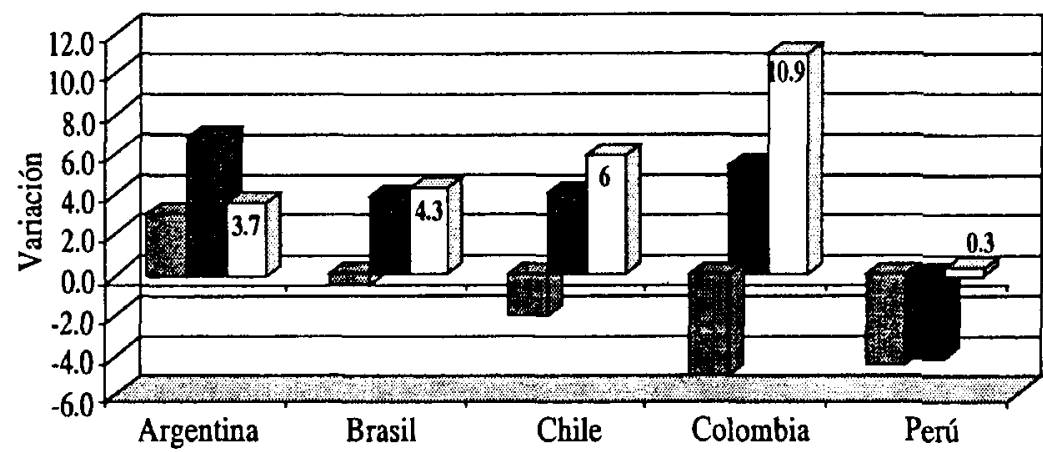

Costo laboral $98 \square$ Productividad $98 \square$ Competitividad 98




\section{CONCLUSIONES}

El análisis efectuado en este trabajo permite llegar al menos a cinco conclusiones. En primer lugar, hubo un cambio en la composición del empleo asalariado privado según la modalidad de contratación. Aumentó la proporción de asalariados con contrato temporal y sin contrato (excepto en Colombia en este último caso) y disminuyó la de asalariados con contrato por tiempo indefinido.

En segundo lugar, en algunos países se redujeron las alícuotas correspondientes a las contribuciones de los empleadores para los asalariados con contratos temporales promovidos por la ley.

En tercer lugar, y como consecuencia de lo anterior, el costo laboral medio (que resulta de ponderar el costo laboral según modalidad de contratación por su importancia en el empleo), aumentó menos de lo que habría crecido de no haberse producido un cambio en la composición del empleo asalariado y de no haberse acentuado las diferencias salariales. Como consecuencia, algunos países obtuvieron ganancias de competitividad superiores a las que habrian obtenido de no haberse producido dichos cambios, mientras que otros tuvieron pérdidas de competitividad inferiores a las que habrían tenido. La única excepción fue Colombia, donde los cambios ocurridos llevaron a un aumento del costo laboral ligeramente superior al que se habría producido sin los cambios.

En cuarto lugar, aun en aquellos países en los que se observaron pérdidas de competitividad (Brasil, Colombia y Perú), ellas no se debieron a una caída de la productividad, sino al aumento acelerado del costo laboral expresado en dólares corrientes. Este crecimiento obedeció en parte al aumento de los salarios reales, pero principalmente al rezago cambiario que encareció significativamente el costo laboral. Como se vio en la sección anterior, la corrección de dicho rezago en 1998 permitió reducir el costo laboral y, por esa vía, compensar parcialmente la pérdida de competitividad generada por las maxidevaluaciones registradas en los países del sudeste asiático.

En quinto lugar, la recuperación de la competitividad perdida tras la crisis asiática y, más recientemente, tras las turbulencias en Brasil, no parecería poder sustentarse en un crecimiento espectacular de la productividad ni la reducción de los costos laborales mediante una mayor precarización 
del empleo, una contracción de los salarios nominales o una baja significativa de las contribuciones patronales. ${ }^{13}$ En estas circunstancias, las ganancias de competitividad deberían sustentarse, en el corto plazo, en un redireccionamiento de las políticas cambiarias y de tasas de interés $y$, en el largo plazo, en una estrategia para acrecentar la productividad que involucre a empresarios y trabajadores.

Ahora bien, tal estrategia incidiría en la política laboral en el campo de las relaciones de trabajo, tanto individuales como colectivas. En lo que se refiere a las relaciones individuales, preocupan los efectos de la precarización del empleo tanto sobre las condiciones de seguridad y el desarrollo personal y familiar del trabajador, como sobre el desarrollo de su potencial de productividad, más aún si sus posibilidades de participar en programas y actividades de capacitación y recalificación laboral son limitadas.

Habría que examinar la conveniencia de disminuir la contratación temporal y de otorgar incentivos al empleo estable mediante la reducción del costo de los contratos de más largo plazo. Además, se debería desarrollar mecanismos de protección a los desempleados, combinados con programas de capacitación para los que reciban dicha prestación: programas que faciliten la "empleabilidad" de los trabajadores y que, por ser obligatorios mientras se reciba la prestación, contribuyan a desalentar el desempleo de larga duración.

Las relaciones colectivas de trabajo, y más especificamente la negociación colectiva, es el segundo campo en el que se requiere intervenir para elevar la productividad. De la negociación colectiva mirada como un medio para evitar la sobreexplotación de los trabajadores y lograr la paz laboral, se debe pasar a la negociación colectiva visualizada como la búsqueda de compromisos entre trabajadores y empresarios para aplicar estrategias que conduzcan a mejorar la productividad y a distribuir más equitativamente los beneficios que se generen.

Una de estas estrategias podría ser la vinculación entre los salarios y la productividad, de tal manera que, fijando un piso determinado por cel

13 Lo que no quiere decir que no se deba hacer un esfuerzo por reducir o eliminar aquellas contribuciones que no generan un beneficio para el trabajador, en especial en el caso de las microempresas y pequeñas empresas. 
nivel salarial» hasta entonces vigente, todo aumento de salario durante el período acordado se relacione con los incrementos de productividad que se obtengan, medidos según fórmulas convenidas entre las partes.

Una segunda estrategia negociada entre empleadores y trabajadores podría ser la de fomentar la participación de estos últimos en las decisiones sobre la organización de las distintas fases del proceso de producción y sobre el control de calidad, y la de establecer incentivos a la formulación de propuestas que contribuyan a elevar la productividad.

Asimismo, mediante la negociación colectiva podrian establecerse planes concertados de capacitación dentro de las empresas que, al igual que los incentivos, redundarian en aumentos de productividad a corto y a largo plazo.

En suma, la recuperación de la competitividad perdida y el logro de nuevos avances en la competitividad debiera basarse más en aumentos de productividad que en reducciones de costos resultantes de una mayor precarización laboral o un menor nivel de empleo. Una mayor seguridad en el empleo y la promoción de la negociación colectiva pueden contribuir a alcanzar aumentos sostenidos en la productividad.

\section{Bibliografía}

Amadeo, E., J.J. Camargo, R. Frenkel, E. Hernández-Laos

1999 Apertura comercial, productividad y empleo. Lima: Organización Internacional del Trabajo (OIT).

Chacaltana, J.

1999 "Costos laborales en Perú». En V.E. Tokman y D. Martínez (comps.). Costos laborales sectoriales y modalidades de contratación. Lima: OIT (en prensa).

CHACÓN, B.

1999 "Costos laborales en Chile». En V.E. Tokman, D. Martínez (comps.). Costos laborales sectoriales y modalidades de contratación. Lima: OIT (en prensa). 
CEPAL (Comisión Económica para América Latina y el Caribe)

1998 Anuario estadístico de América Latina y el Caribe 1997. Santiago de Chile.

Hofman, A.

1996 "The historical experience: growth accounting". En Ruud Buitelaar y Pitou Van Dijck (eds.). Latin America's New Insertion in the World Economy-Towards Systemic Competitiveness in Small Economies. Macmillan.

Pochman, $M$.

1999 "Costos laborales en Brasil». En V.E. Tokman y D. Martínez (comps.). Costos laborales sectoriales y modalidades de contratación. Lima: OIT (en prensa).

OIT

1997 Costos laborales y competitividad industrial en América Latina. Lima.

1998 Panorama laboral '98. Ginebra.

SzRetTer, $H$.

1999 "Costos laborales en Argentina". En V.E. Tokman y D. Martínez (comps.). Costos laborales sectoriales y modalidades de contratación. Lima: OIT (en prensa).

ToKman, V.E. y D. Martinez

1998 La agenda laboral en la globalización. Eficiencia económica con progreso social. Viña del Mar.

Tokman, V.E. y D. Martínez (comps.)

1999 La flexibilización en el margen. La reforma del contrato de trabajo. Lima: OIT. 